\title{
Functional Assessment of the Cervical Spine in F-16 Pilots With and Without Neck Pain
}

\author{
Veerle De loose, Marieke Van den Oord, \\ Frédéric BurnotTe, DAMien VAN Tiggelen, \\ Veerle Stevens, Barbara Cagnie, Lieven Danneels, \\ AND ERIK WitVROUW
}

\begin{abstract}
De loose V, Van den Oord M, Burnotte F, Van Tiggelen D, Stevens V, Cagnie B, Danneels L, Witvrouw E. Functional assessment of the cervical spine in F-16 pilots with and without neck pain. Aviat Space Environ Med 2009; 80:477-81.

Introduction: Spinal symptoms in fighter pilots are a serious aeromedical problem. The most common neck complaints are muscular pain and strain. The aim of the current study was to determine possible differences in the cervical range of motion (CROM), neck position sense, and neck muscle strength between pilots with and without neck pain. Methods: There were 90 male F-16 pilots who volunteered, of which 17 had experienced bilateral neck pain. A standardized questionnaire was used to collect personal information. The maximum isometric neck flexion/extension and lateral flexion strength, the neck position sense, and the cervical range of motion were measured. Results: There were no significant differences between healthy pilots and those with neck pain concerning neck muscle strength and neck position sense. The neck pain group had a limited CROM in the sagittal plane $\left(130^{\circ} ; \mathrm{Cl}: 116^{\circ}\right.$ $\left.144^{\circ}\right)$ and in the transversal plane $\left(155^{\circ} ; \mathrm{Cl}: 140^{\circ}-170^{\circ}\right)$ compared to the healthy pilots. Discussion: In the current study we screened for different motor skills so that deficits could be detected and retraining programs could be implemented when necessary. According to our results, individual retraining programs might reduce neck pain and therefore a well-instructed training program to maintain a proper active CROM should be implemented. Future studies should investigate the effectiveness of this kind of program.
\end{abstract}

Keywords: strength, proprioception, mobility, rehabilitation.

TECK PAIN IN association with the dynamic work environment of the fighter pilot is a well-discussed issue. Spinal symptoms in these pilots have been recognized as a serious medical problem $(2,21,25)$. The most common neck complaints are muscular pain and strain. Electromyography (EMG) investigations have been able to show that pilots exposed to high $G$ forces over repeated, short periods use close to $100 \%$ of their neck extensor muscle strength. When in-flight EMG recordings of the cervical muscles where analyzed, investigators found higher demands on strength and endurance in pilots than in the average person $(15,26)$. Often described, flight-specific contributing factors of neck pain in the pilot population are head movements under high $+G_{z}$ load, seat-back angle, forward bent posture, head worn equipment, the use of night vision goggles, and numbers of flight hours $(14,15)$. According to the literature, pilot's lack of muscular force and endurance of the cervical musculature could be one of the main risk factors causing neck pain. As a consequence, neck strengthening exercises are often recommended in the prevention of neck complaints in fighter pilots $(5,11,31)$. Although, other motor control impairments such as lack of range of motion, poor proprioception or muscular coordination and muscular imbalance could also play an important role in the occurrence of neck pain $(6,7)$.

In the current study a battery of tests was developed for the functional assessment of the cervical spine in order to provide a proper preventive training program for F-16 pilots. Our study was based on the injury prevention research of Van Tiggelen et al. (32). In that study, the authors declared that prior to introducing preventive measures to the pilots, the etiology and consequences of the neck pain in this population need to be identified. The preventative measures must be based upon the data collected during the functional assessment of the cervical spine.

Therefore, the main purpose of the current study was to determine possible differences in the cervical range of motion (CROM), neck position sense, and the neck muscle strength between pilots with and without neck pain.

\section{METHODS}

\section{Subjects}

The current study was a collaborative effort between the Belgian Air Force and the Royal Netherlands Air Force, both of which operate the F-16 Fighting Falcon. The squadrons received a medical briefing introducing the study. There were 90 F-16 pilots who signed informed consent forms and participated in this study. The Ethical Research Committee of the Belgian Defense and of Ghent University obtained approval for the study.

All tests were performed on the same day and the pilots were instructed not to fly on the day of the test.

From the Medical Component, Belgian Defense, Military Hospital of Base Queen Astrid, Brussels, Belgium.

This manuscript was received for review in August 2008. It was accepted for publication in January 2009.

Address reprint requests to: Damien Van Tiggelen, Belgian Defense, Medical Component, Military Hospital of Base Queen Astrid, Bruynstraat 2, 1120 Brussels, Belgium; damien.vantiggelen@mil.be.

Reprint \& Copyright (C) by the Aerospace Medical Association, Alexandria, VA.

DOI: 10.3357/ASEM.2408.2009 
The anonymity of the participating pilots was guaranteed by using a unique identifying code. A standardized questionnaire was used to collect information concerning anthropometrical properties, hand dominance, the frequency of exercising, number of flight hours, use of night vision goggles, nature of neck pain, prevention strategies and treatment. Pilots were divided in two groups: a neck pain group (NPG) and a healthy group (HG). To be eligible for the neck pain group, pilots had to have experienced more than two episodes of neck pain lasting at least $1 \mathrm{~d}$ during the past 12 mo $(9,12,13)$. More details about the self-reported 1-yr prevalence of neck pain in these pilots were published previously (13). Table I summarizes the groups' anthropometrical data and the weekly frequency of exercising. Table II summarizes the flight profiles.

\section{Strength}

The maximum isometric neck muscle strength was measured with a David F-140 device (David International, Ltd., Germany). The subjects were sitting in an upright position with stretched legs, only the heels touched the floor and the arms remained relaxed against the side of the body. The seat height, motion axis of C7-T1 (in line with the axis of the movement arm of the testing unit), and chest support were adjusted for each subject. Before any measurements were taken, the subjects performed standardized warm-up exercise for the neck and shoulders. The isometric tests were performed in four directions: flexion, extension, and left and right lateral flexion. The subjects were encouraged to press their head against the resistance pad with increasing force up to a maximum voluntary contraction of $6 \mathrm{~s}$. Within one series there were $30 \mathrm{~s}$ of rest; between the different directions there was a rest period of $3 \mathrm{~min}$. Three maximum voluntary isometric contractions (MVIC) were executed in each direction. The highest peak value (Nm) was used for further analysis. The reproducibility and reliability were confirmed by pilot tests on 15 healthy civilian volunteers. The single-measure ICC ranged from 0.94 to 0.95 for the peak value $(\mathrm{Nm})$ of the different strength tests for both the reproducibility and the reliability.

\section{Neck Position Sense}

The neck position sense was measured with the threedimensional motion analyzer Zebris CMS20 using Windata version 2.20 (Zebris Medizinetechnik $\mathrm{GmbH}$, Isny, Germany). This analyzer consists of a helmet and a triple trunk, each with three ultrasound microphones. The subjects were blindfolded and seated in an upright position on a stool without backrest. Their hands were placed on the thighs; hips and knees were bended $90^{\circ}$. The point of departure was that the pilots defined the neutral position of their necks. The test consisted of two parts. In the first part, the pilots were instructed to return to their own neutral position after an active submaximum range cervical flexion-extension and right and left rotation. In the second part, the pilots were asked to return to a position defined by a researcher $\left(30^{\circ}\right.$ right or left rotation). For the first part the absolute reposition error was calculated in the sagittal plane and transversal plane as a mean of 10 repetitions. For the second part the absolute reposition error was calculated in the transversal plane for right and left rotation as a mean of 5 repetitions in each direction. The reproducibility and reliability were confirmed by pilot tests on 15 healthy civilian volunteers. The exact single-measure ICC for the reposition error to the neutral position was 0.87 for the reproducibility and 0.72 for the reliability. For the absolute reposition error in the repeated-matching test to $30^{\circ}$ rotation the exact ICC for the reproducibility was 0.67 and for the reliability 0.61 .

\section{Range of Motion}

The active cervical range of motion (CROM) was measured with the three-dimensional motion analyzer Zebris CMS20, WinSpine version 1.79 (Zebris Medizinetechnik $\mathrm{GmbH}$, Isny, Germany). The subjects were positioned as above for the neck position sense but without the blindfold. To be sure that the subjects' departure position between the different movement directions was the same, a narrow mirror was placed so that the subject was able to see his own eyes in this position. The device was calibrated before the start of the first movement. After every movement the subjects were asked to look at their eyes in the mirror. The maximal full CROM was measured for

TABLE I. SUMMARY OF GROUPS' ANTHROPOMETRICAL DATA AND THE WEEKLY FREQUENCY OF EXERCISING.

\begin{tabular}{|c|c|c|c|c|}
\hline & \multicolumn{2}{|c|}{$\mathrm{HG}^{*}$} & \multicolumn{2}{|c|}{$\mathrm{NPG}^{+}$} \\
\hline Younger than $30 \mathrm{yr}$ & $48 \%$ & & $41 \%$ & \\
\hline Between 30 and $39 \mathrm{yr}$ & $47 \%$ & & $56 \%$ & \\
\hline Between 40 and $49 \mathrm{yr}$ & $6 \%$ & & $3 \%$ & \\
\hline BMI & 24 & $22.5-25.7$ & 24 & $21.4-27$ \\
\hline Weekly frequency of exercising & 3.3 & $1.3-5.3$ & 2.6 & $4.1-1.1$ \\
\hline
\end{tabular}

* Healthy Group; ${ }^{\dagger}$ Neck Pain Group; ${ }^{\ddagger}$ Confidence Interval. 
TABLE II. SUMMARY OF GROUPS' FLIGHT PROFILES.

\begin{tabular}{|c|c|c|c|c|c|}
\hline & \multicolumn{2}{|c|}{$\mathrm{HG}^{*}$} & \multicolumn{2}{|c|}{$\mathrm{NPG}^{+}$} & \multirow[b]{2}{*}{$P$-Value } \\
\hline & Hours & $95 \% \mathrm{Cl}^{\ddagger}$ & Hours & $95 \% \mathrm{Cl}^{\ddagger}$ & \\
\hline Total Flight Time & 1613 & $646-2581$ & 1745 & $826-2666$ & 0.612 \\
\hline Total F-16 Time & 984 & $210-1758$ & 962 & 408-1516 & 0.916 \\
\hline Weekly & 3.3 & $1-5.6$ & 2.6 & $1.4-3.8$ & 0.500 \\
\hline Years Fighter Pilot & 9.5 & $4.1-14.9$ & 9.7 & $4.5-14.9$ & 0.857 \\
\hline
\end{tabular}

* Healthy Group; ${ }^{+}$Neck Pain Group; ${ }^{\ddagger}$ Confidence Interval.

flexion - extension, right - left rotation, and right - left lateral flexion. Each measurement consisted of three repetitions for each movement. For each direction the mean of three repetitions was recorded. The repeatability and reproducibility of the CROM test is described by Cagnie et al. (10) and was shown to be highly reliable. ICC ranged from 0.92 to 0.94 for the reproducibility and ranged from 0.80 to 0.87 for the repeatability.

The different parts of the functional assessments were conducted in an arbitrary sequence. To avoid the influence of muscular fatigue on the other tests, the muscular strength was always measured at the end of the evaluation. Each assessment had two permanent examiners; they were blinded to the pilots' history of neck pain.

\section{Statistics}

Statistical analyses were performed with SPSS 15.0 software package (SPSS Inc., Chicago, IL). Mean differences with $95 \%$ CI were given as descriptive statistics. In all tests, $P<0.05$ was considered statistically significant. All data were normally distributed (Kolmogorov-Smirnov test and Levene's test). Parametric statistics were applied. Independent sample's $t$-tests were performed to analyze differences between healthy and neck pain pilots concerning the strength and the mobility. For analysis of the reproducibility and the repeatability, intraclass correlation coefficients (ICC) were used.

\section{RESULTS}

There were no significant differences between the HG and the NPG pilots concerning neck muscle strength. The mean values for HG and NPG, respectively, were as follows: extension muscles, $60 \mathrm{Nm}$ (CI: 44-76) and 56 $\mathrm{Nm}$ (CI: 40-72); flexion muscles, $26 \mathrm{Nm}$ (CI: 16-46) and $25 \mathrm{Nm}$ (CI: 15-35); right lateral bending muscles, $31 \mathrm{Nm}$ (CI: 16-46) and $33 \mathrm{Nm}$ (CI: 18-48); left lateral bending muscles, $31 \mathrm{Nm}$ (CI: 17-45) and $31 \mathrm{Nm}$ (CI: 17-45).

There were no significant differences between the HG and the NPG concerning neck position sense. After a submaximal flexion-extension movement the mean reposition error in the sagittal plane for the HG measured $2.83^{\circ}$ (CI: 1.51-4.15), and $2.64^{\circ}$ (CI: 1.38-3.9) for the NPG. After a submaximal right and left rotation the mean reposition error in the transversal plane for the HG measured $2.1^{\circ}$ (CI: 0.91-3.29) and $1.68^{\circ}$ (CI: 1.22-2.14) for the NPG.

There were no differences in neck position-matching accuracy when the pilots performed the test to the neu- tral position or to the $30^{\circ}$ rotation. The reposition error in the transversal plane for the HG and NPG, respectively, were as follows: return to $30^{\circ}$ rotation on the right side, $2.51^{\circ}$ (CI: $1.27-3.75$ ) and $2.62^{\circ}$ (CI:1.41-3.83); return to $30^{\circ}$ rotation on the left side, $2.67^{\circ}$ (CI: $\left.0.72-4.62\right)$ and 2.28 (CI:1.34-3.22).

The only statistically significant difference between both groups was that the NPG had a decreased CROM in both the sagittal plane $(P=0.012)$ and transversal plane $(P=0.044)$ compared to the HG. The mean CROM for the HG and NPG, respectively, were as follows: sagittal plane, $140^{\circ}$ (CI: 125-155) and $130^{\circ}$ (CI: 116-144); transversal plane, $162^{\circ}$ (CI: 148-176) and $155^{\circ}$ (CI: 140170); frontal plane, $87^{\circ}$ (CI: 71-103) and $89^{\circ}$ (CI: 73-105).

\section{DISCUSSION}

Neck pain and relatively minor cervical spine softtissue injuries have been frequently described in fighter pilots $(3,22,30)$. Another well-documented problem in the fighter pilot's cervical spine is the premature onset of degenerative changes in the cervical spine $(18,19)$. As a result, deficits in the motor skills of the fighter pilot's cervical spine can be expected (6).

In the current study the maximum isometric neck muscle strength was measured. No significant differences were observed between the healthy and neck pain pilots. These results confirm findings of previously published studies $(2,16)$.

Some studies suggest that increased muscle strength may reduce muscle strain under $+G_{z}$ loading. Based on the observation that fighter pilots with neck pain had significantly less neck muscle strength, neck-strengthening exercises were encouraged (5). Oksa et al. (26) support neck-strengthening exercises after observations of inflight EMG measurements because the magnitude of the peak strain level was extremely high. This emphasizes the fact that the neck musculature of fighter pilots is subjected to very high demands (26). They concluded that repeated sorties, such as aerial combat maneuvering exercises several times a day, cause fatigue. This muscle fatigue was most noticeable in the neck musculature (27). Strengthening programs have been suggested to decrease the fatigability of the pilot's neck musculature. Some specific neck strengthening programs in fighter pilots have resulted in increases in neck muscle strength $(2,5,31)$. Burnett et al. concluded that the natural strength adaptation of the cervical muscles to the $+G_{z}$ environment 
associated with flight training is rather limited. To cope with the loads placed on the cervical spine during more advanced high-performance flying, a specific neckstrengthening program was recommended for the pilots throughout the flight-training course (8).

In the current study no differences were observed between the healthy pilots and those with neck pain regarding the neck position sense in the sagittal and the horizontal plane. These results are in agreement with other neck position-sense investigations. These other studies did not observe any differences in the neck position-sense accuracy between neck pain patients and healthy individuals $(7,29)$. In contrast, other researchers did observe greater reposition errors in the subjects with pathology of the cervical spine $(23,28)$. However, the population of the latter studies had more serious pathology than our neck pain pilots. In the current study, the position within the range of motion did not influence the position-sense accuracy. These findings are in agreement with the findings of Armstrong et al. (7). Little has been published concerning the effects of position-sense retraining. To the best of our knowledge, no literature is available concerning neck position-sense retraining and fighter pilots.

In our study we observed limitations in the CROM in the sagittal and the transversal plane in the NPG. No differences in the frontal plane were observed. These results are in agreement with those of Armstrong et al., who investigated the differences in CROM between whiplash patients and healthy individuals. Whiplash patients displayed significantly less flexion, extension, and left and right rotation, and no significant differences were observed when comparing lateral flexion recorded with the healthy group (7). We used the same study design as Cagnie et al., who observed a limitation in the CROM in the transversal plane in individuals with idiopathic neck pain compared to healthy subjects (10). The results of our study are in contrast with the results of previous studies concerning CROM in fighter pilots. These other investigators concluded that the groups with and without experience of acute in-flight neck pain did not differ concerning the CROM $(16,17)$. One has to bear in mind that other methods were used, e.g., subjects were student fighter pilots and the passive CROM was measured.

The reason for the limited CROM in the neck pain group is unknown. Possible suggestions are that the decrease might be caused by shortened neck musculature or degenerative changes brought on by flying highperformance aircraft.

Stretching is generally believed to promote better performance of the neck muscles, which is necessary during high $+\mathrm{G}_{\mathrm{z}}$ flight to prevent acceleration-induced neck injuries $(11,26,27)$. There are contradictory opinions on this, however. Several authors suggested that stretching had a beneficial effect on injury prevention, while others suggested that stretching before exercise did not prevent injury (4). In a previous study, fighter pilots were questioned about their current preventive measures for neck injury. This questionnaire revealed that pilots routinely performed stretching before flying. Yet pilots who performed preflight stretching had no fewer complaints (13) than those who did not. Newman concluded that preflight stretching might not be protective in terms of G-induced neck injury (25). In the survey of Jones et al., preflight stretching did not appear to prevent flight-related pain; however, a more defined preflight stretching routine was recommended as a part of a potentially effective prevention strategy (20). One survey of 268 pilots showed that preflight range-of-motion stretching had a beneficial effect (1).

The current study revealed that the active CROM was limited in the sagittal and the transversal plane in the neck pain pilots. Little has been published about the changes in the CROM following stretching exercises. McCarthy et al. examined the effect of a stretching program on the active cervical rotation. Stretching exercises for the cervical spine did increase the active CROM in the transversal plane. Importantly, to maintain this effect these stretching exercises must be performed regularly (24). This might indicate that stretching, as a part of an effective preventive strategy, could contribute significantly. The evidence regarding the effect of stretching on pain is unclear (4). However, according to our results, a well-instructed stretching program could be implemented in the fighter pilot's training program in order to maintain a proper active CROM.

As mentioned above, different approaches to the prevention of neck pain in fighter pilots have been shown to have their benefits. As not all pilots develop neck pain, not all pilots will have benefits from these approaches. The strength of the current study is that it assessed different motor skills of the fighter pilots' cervical spine. To the best of our knowledge this is the first study in this population that combined the assessment of different motor skills. Thus, deficits could be detected and retraining programs could be implemented when necessary. This kind of individual retraining program might reduce neck pain. Additional studies to investigate the effectiveness of this type of program in this population are needed. These programs should take the high in-flight demands on the fighter pilots cervical spine into consideration.

The present results must be viewed within the limitations of the study. Only 17 of 90 F-16 pilots experienced neck pain; this could form a limitation to the conclusion drawn. The current study did not monitor the flying abilities and different movement strategies of the pilots during flight.

The current study established that many factors can contribute neck pain in F-16 pilots. No general preventive program exists that will suit all pilots; therefore an individualized program should be introduced. Future research should evaluate the effectiveness of the implemented interventions.

\footnotetext{
ACKNOWLEDGMENTS

The authors want to thank COL Laire, all subjects, and all coworkers who made this study possible.

Authors and affiliations: Veerle De Loose, PT, Frederic Burnotte, PT, Damien Van Tiggelen, PT, and Veerle Stevens, PT, Ph.D., Medical
} 
Component, Belgian Defense, Military Hospital of Base Queen Astrid, Brussels, Belgium; Marieke Van den Oord, M.Sc., Center for Man and Aviation, Royal Netherlands Air Force, Soesterberg, The Netherlands; and Barbara Cagnie, PT, Ph.D., Lieven Danneels, PT, Ph.D., and Erik Witvrouw, PT, Ph.D., Department of Rehabilitation Sciences and Physiotherapy, Ghent University Hospital, Ghent, Belgium.

\section{REFERENCES}

1. Albano JJ, Stanford JB. Prevention of minor neck injuries in F-16 pilots. Aviat Space Environ Med 1998; 69:1193-9.

2. Alricsson M, Harms-Ringdahl K, Schüldt K, Ekholm J, Linder J. Mobility, muscular strength and endurance in the cervical spine in Swedish air force pilots. Aviat Space Environ Med 2001; 72:336-342.

3. Andersen HT. Neck injury sustained during exposure to high-G forces in the F16B. Aviat Space Environ Med 1988; 59:356-8.

4. Andersen JC. Stretching before and after exercise: effect on muscle soreness an injury risk. J Athl Train 2005; 40:218-20.

5. Äng B, Linder J, Harms-Ringdahl K. Neck strength and myoelectric fatigue in fighter and helicopter pilots with a history of neck pain. Aviat Space Environ Med 2005; 76:375-80.

6. Armstrong B, McNair P, Taylor D. Head and neck position sense. Sports Med 2008; 38:101-17.

7. Armstrong BS, McNair PJ, Williams M. Head and neck position sense in whiplash patients and healthy individuals and the effect of the cranio-cervical flexion action. Clin Biomech (Bristol, Avon) 2005; 20:675-84.

8. Burnett AF, Naumann FL, Burton EJ. Flight-training effect on the cervical muscle isometric strength of trainee pilots. Aviat Space Environ Med 2004; 75:611-5.

9. Cagnie B, Danneels L, Van Tiggelen D, De Loose V, Cambier D. Individual and work related risk factors for neck pain among office workers: a cross sectional study. Eur Spine J 2007; 16: 679-86.

10. Cagnie B, Cools A, De Loose V, Cambier D, Danneels L. Reliability and normative database of the Zebris cervical range-of-motion system in healthy controls with preliminary validation in a group of patients with neck pain. J Manipulative Physiol Ther 2007; 30:450-5.

11. Coakwell MR, Bloswick DS, Moser R, Jr. High-risk head and neck movements at high $\mathrm{G}$ and interventions to reduce associated neck injury. Aviat Space Environ Med 2004; 75:68-80.

12. De Loose V, Burnotte F, Cagnie B, Stevens V, Van Tiggelen D. Prevalence and risk factors of neck pain in military office workers. Mil Med 2008; 173:474-9.

13. De Loose V, Van den Oord M, Burnotte F, Van Tiggelen D, Stevens $\mathrm{V}$, Cagnie B, et al. Individual, work and flight-related issues in F-16 pilots reporting neck pain. Aviat Space Environ Med 2008; 79:779-83.

14. Green NDC. Acute soft tissue neck injury from unexpected acceleration. Aviat Space Environ Med 2003; 74:1085-90.

15. Hamalainen $\mathrm{O}$, Vanharanta $\mathrm{H}$. Effect of $\mathrm{Gz}$ forces and head movements on cervical erector spinae muscle strain. Aviat Space Environ Med 1992; 63:709-16.
16. Hamalainen O, Vanharanta H, Bloigu R. Determinants of + Gzrelated neck pain: a preliminary survey. Aviat Space Environ Med 1993; 64:651-2.

17. Hämäläinen $\mathrm{O}$, Vanharanta $H$, Bloigu R. + Gz-related neck pain: a follow-up study. Aviat Space Environ Med 1994; 65:16-8.

18. Hanada K, Kitada A, Yoshihara Y,Tachibana S, Nagaoki H. Neck pain and degenerative cervical disks in fighter pilots. [Jap] Japanese Defense Forces Medical Journal [Boei Eisei] 2000; 47:221-5.

19. Hendriksen IJ, Holewijn M. Degenerative changes of the spine of fighter pilots of the Royal Netherlands Air Force (RNLAF). Aviat Space Environ Med 1999; 70:1057-63.

20. Jones JA, Hart SF, Baskin DS, Effenhauser R, Johnson SL, Novas MA, et al. Human and behavioral factors contributing to spine-based neurological cockpit injuries in pilots of highperformance aircraft: recommendations for management and prevention. Mil Med 2000; 165:6-12.

21. Kikukawa A, Tachibana S, Yagura S. G-related musculoskeletal spine symptoms in Japan Air Self Defense Force F-15 pilots. Aviat Space Environ Med 1995; 66:269-72.

22. Knudson R, McMillan D, Doucette D, Seidel M. A comparative study of G-induced neck injury in pilots of the F/A-18, A-7, and A-4. Aviat Space Environ Med 1988; 59:758-60.

23. Loudon JK, Ruhl M, Field E. Ability to reproduce head position after whiplash. Spine $1997 ; 22: 865-8$.

24. McCarthy PW, Olsen JP, Smeby IH. Effects of contract - relax stretching procedures on active range of motion of the cervical spine in the transverse plane. Clin Biomech (Bristol, Avon) $1997 ; 12: 136-8$.

25. Newman DG. + GZ-induced neck injuries in Royal Australian Air Force fighter pilots. Aviat Space Environ Med 1997; 68: $520-4$.

26. Oksa J, Hämäläinen $\mathrm{O}$, Rissanen $\mathrm{S}$, Myllyniemi J, Kuronen P. Muscle strain during aerial combat maneuvering exercises. Aviat Space Environ Med 1996; 67:1138-43.

27. Oksa J, Hämäläinen $\mathrm{O}$, Rissanen $\mathrm{S}$, Salminen $\mathrm{M}$, Kuronen $\mathrm{P}$. Muscle fatigue caused by repeated aerial combat maneuvering exercises. Aviat Space Environ Med 1999; 70:556-60.

28. Revel M, Andre-Deshays C, Minguet M. Cervicocephalic kinaesthetic sensibility in patients with cervical pain. Arch Phys Med Rehabil 1991; 72:288-91.

29. Rix GD, Bagust J. Cervicocephalic kinesthetic sensibility in patients with chronic, nontraumatic cervical spine pain. Arch Phys Med Rehabil 2001; 82:911-9.

30. Schall DG. Non-ejection cervical spine injuries due to $+\mathrm{Gz}$ in high performance aircraft. Aviat Space Environ Med 1989; 60:445-56.

31. Sovelius R, Oksa J, Rintala H, Huhtala H, Ylinen J, Siitonen S. Trampoline exercise vs. strength training to reduce neck strain in fighter pilots. Aviat Space Environ Med 2006; 77:20-5.

32. Van Tiggelen D, Wicks S, Stevens V, Roosen P, Witvrouw E. Risk taking behaviour integrating efficacy, efficiency, compliance and effective prevention of sports injuries: a model. Br J Sports Med 2008; 42:648-52. 